\title{
Controle da ansiedade materna de bebê pré-termo via contato lúdico-gráfico'
}

\section{Control of maternal anxiety in respect of pre-term babies using drawing game intervention}

\author{
Rosely Aparecida Prandi PERRONE² \\ Vera Barros de OLIVEIRA ${ }^{2}$
}

\begin{abstract}
Resumo
Investiga-se a influência de intervenção lúdico-gráfica no controle da ansiedade de mães de bebês pré-termo. Trata-se de estudo qualitativo, exploratório descritivo. Participam 30 mães. Levanta-se inicialmente o perfil gestacional, o estado emocional com a Escala de Ansiedade, Depressão e Irritabilidade e a expectativa quanto ao bebê, com o Inventário de Percepção Neonatal. Realizam-se a seguir 16 intervenções grupais com atividades gráficas e lúdicas, sensório-motoras, simbólicas e de regras, segundo fundamentação piagetiana. O perfil traçado revela antecedentes de gravidez de risco. A escala aponta 75\% das mães com alta ansiedade e depressão; o inventário mostra, contudo, expectativas positivas quanto aos bebês. A análise interventiva revela boa adesão, com progressiva motivação, descontração, interação, liberação de conteúdos ansiógenos e angustiantes relativos ao descompasso entre o bebê esperado e o real, ao sentimento de culpa, ao desconforto em lidar com um bebê frágil, favorecendo assumir sua maternidade com menos ansiedade.
\end{abstract}

Unitermos: Ansiedade. Brincar. Desenho. Prematuro.

\begin{abstract}
This research studies the influence of a drawing game intervention for control of anxiety in mothers with hospitalized, pre-term babies. It is a qualitative, exploratory and descriptivestudy, in which 30 mothers participated. Initially the gestational profile was evaluated; the emotional state was then measured using the Irritability-Depression-Anxiety Scale and expectations regarding the baby, using the Neonatal Perception Inventory. 16 group interventions were then performed, with drawing game, sensorimotor, symbolic and rule activities, following Piagetian fundamentals. The outlined profile revealed previous history of pregnancy risk. The scale revealed that $75 \%$ of mothers suffered from high anxiety and depression; nevertheless, the inventory presented positive expectations with regard to their babies. The intervention was well accepted, with progressive motivation, relaxation, interaction, release of anxiogenic and distressing content related to the discrepancy between the expected baby and the actual baby, and to the feeling of guilt and discomfort in dealing with a fragile baby, resulting in a less anxious acceptance by the mothers.
\end{abstract}

Uniterms: Anxiety. Recreation. Drawing. Infant, premature.

Grv

' Artigo elaborado a partir da dissertação de R.A.P. PERRONE, intitulada "Intervenção lúdicas com mães de recém-nascidos pré-termo hospitalizados". Universidade Metodista de São Paulo, 2008.

2 Universidade Metodista de São Paulo, Faculdade de Ciências da Saúde, Curso de Mestrado em Psicologia da Saúde. Av. Dom Jaime de Barros Câmara, 1000, Planalto, 09895-400, São Bernardo do Campo, SP, Brasil. Correspondência para/Correspondence to:V.B. OLIVEIRA. E-mail: <vera.barros.oliveira@terra.com.br>. 
Anualmente, 20\% de bebês nascem prematuros em todo mundo (Brasil, 2002), sendo a principal população atendida em unidades neonatais. Trata-se de um grupo amplo e heterogêneo, incluindo bebês entre o limite da viabilidade próximo ao termo, que apresentam características fisiológicas e patológicas próprias e variadas (Goulart, 2004). No Brasil, a incidência de nascimentos pré-termo depende inclusive das características da população estudada (Valle, 2002). Estudo analisando variáveis sociais e perinatais das relações afetivas entre mães e recém-nascidos a termo e pré-termo constatou que todas as mães estabeleceram ligações afetivas com seus bebês, mesmo em gravidez não planejada, contudo, a relação das mães pré-termo, revelou-se mais difícil (Thomaz, Lima, Tavares \& Oliveira, 2005).

O parto prematuro, que resulta num recém-nascido frágil e pequeno, gera sentimentos de incompetência, frustração e ansiedade (Padovani, Linhares, Carvalho, Duarte \& Martinez, 2004). É o começo de um período estressante para os pais, que têm sua percepção afetada em relação a seu bebê (Gasparetto, 1998; Valle, 2002). Vizziello, Rebecca e Calvo (2001), em estudo realizado com recém-nascidos a termo e pré-termo mostram diferenças quanto ao apego e verificam que experiências maternas traumáticas geram uma tendência à formação de um vínculo desorganizado. Quadros clínicos e patológicos decorrentes ou associados a complicações neonatais podem ocorrer, constituindo fatores de risco ao desenvolvimento dessas crianças (Kliegman, 1996).

Os avanços dos processos de diagnóstico e terapêutica na área da neonatologia e o posterior acompanhamento da evolução em longo prazo de bebês prematuros têm mostrado que a falta de interação mãe-bebê pode levar a desordens no relacionamento entre ambos e prejuízos no processo de desenvolvimento integral da criança, sendo que estes avanços não substituem a presença dos pais e, principalmente da mãe, para o recém-nascido (Casanova, Valle \& Santos, 2002).

Contudo, estudo longitudinal comparativo sobre o desenvolvimento de bebês pré-termo, no primeiro ano de vida, entre dois grupos, um com presença de ansiedade e depressão materna, o que compromete a interação mãe-bebê, e outro sem, não revelou diferença, indicadores de desenvolvimento classificados como Normal (Fraga, Linhares, Carvalho \& Martinez, 2008).

Mães de bebês pré-termo apresentam alta frequência de sintomas de depressão, sendo que este estado emocional gera dificuldade do bebê em desenvolver seu apego à mãe (Poehlmann \& Fiese, 2001).

Estudos indicam a ansiedade, depressão e estresse como as principais reações emocionais de mães de recém-nascidos pré-termo (Melnyk, Crean, Feinstein \& Fairbanks, 2008; Carvalho, Martinez \& Linhares, 2008; Schmücker et al., 2005; Gasparetto, 1998). A associação entre estados de depressão e ansiedade materna com a qualidade da interação mãe-bebê pré-termo também tem sido pesquisada, mostrando indicadores negativos que comprometem essa interação (Ryding, 2008; Thomaz et al., 2005).

Ruiz, Ceriani Cernadas, Cravedi e Rodríguez (2005) avaliaram o impacto de um programa de intervenção psicológica sobre o nível de estresse e depressão de mães de recém-nascidos pré-termo durante a internação de seu bebê e revelam diminuição expressiva dos sintomas após intervenção. Revisão da literatura sobre nascimento de risco aponta que a mãe de um bebê nestas condições necessita de orientação da equipe e apoio emocional durante o trabalho de parto e período pós-parto, para prevenir o surgimento de transtornos gerais do desenvolvimento do bebê (Brum \& Schermann, 2004). Investigação sobre ansiedade em mães de bebês pré-termo demonstrou que os níveis são os mesmos no Brasil e na Dinamarca, evidenciando que as respostas psicossomáticas independem da qualidade dos recursos hospitalares (Valle, 2002).

A interação materna caracteriza-se como uma forma de estimular o recém-nascido, ocasião em que também se pode avaliar o tipo de contato que a mãe estabelece com o bebê e como lida com seus possíveis conflitos, assim como percebe as expressões faciais, vocais e corporais do bebê. Com interação saudável, aspectos psicofuncionais do bebê relativos a sono, respiração, digestão, choro, entre outros, evoluem de forma organizada (Pinto, 2004).

Após a norma de Atenção Humanizada do Recém-Nascido de Baixo Peso - Método Canguru (Brasil, 2002), estudos evidenciam seus benefícios, favorecendo inclusive a estabilidade emocional da mãe (Venâncio \& Almeida, 2004; Cruvinel \& Macedo, 2007). 
O sofrimento psíquico vivido pela mãe que acompanha um filho internado e suas estratégias de enfrentamento foram estudados por Costa, Mombelli e Marcon (2009). A necessidade de uma assistência integral e humanizada, contemplando principalmente as mães de recém-nascidos pré-termo hospitalizados tem sido apontada e programas de informação e suporte psicológico vêm sendo desenvolvidos (Carvalho \& Gomes, 2005).

A utilização de estratégias grupais lúdicas em ambiente hospitalar tem enfocado mais crianças e adolescentes, inclusive em sua interação com a família. Estes estudos têm comprovado como o brincar, em suas diversas modalidades, sensório-motoras, simbólicas ou de sociabilização, favorece a expressão de sentimentos e emoções difíceis de serem verbalizados, assim como contribuem para uma comunicação mais fluente entre pacientes, familiares e equipe de saúde (Oliveira, Dias \& Roazzi, 2003).

Na visão piagetiana, o brincar vem a ser um dos principais vetores do desenvolvimento, com o predomínio do relaxamento sobre a tensão, do prazer sobre o desprazer, da assimilação sobre a acomodação, possibilitando uma adaptação menos sofrida à realidade vivida, num movimento positivo de equilibração do organismo (Piaget, 1973; Piaget, 1978).

Com base nesta sustentação teórica, estudos têm sido desenvolvidos, revelando como intervenções com atividades lúdicas na área da saúde contribuem para manter o equilíbrio interno e ativos os processos de comunicação e expressão. Por conservar características repetitivas e reprodutoras, assim como exploratórias e inovadoras, por conciliar atividades corporais, simbólicas e sociais, facilitam quebras de resistência e propiciam um movimento interativo natural, essencial para o processo de abertura ao meio, principalmente frente a crises, criando condições de auto-regulação para lidar com situações de tensão e frustração, como as presentes no processo de hospitalização, contribuindo inclusive para a aderência à orientação da equipe de saúde.

Pesquisas sobre o brincar nos mais diversos contextos, inclusive o hospitalar, vêm tendo um considerável aumento, sendo o mesmo considerado como uma atividade espontânea, prazerosa, auto-motivada, que facilita a expressão e a comunicação (Vieira \& Carneiro, 2008).
Este estudo teve como objetivo investigar a influência de intervenções lúdico-gráficas com mães de recém-nascidos pré-termo hospitalizados na diminuição de sua ansiedade.

\section{Método}

Este estudo qualitativo, de caráter exploratório descritivo, foi realizado em hospital universitário de cidade de grande porte, com 30 mães na faixa etária de 16 a 40 anos e escolaridade até o $2^{\circ} \mathrm{grau}$, que haviam tido parto prematuro. Todas participavam do Método Mãe-Canguru, uma vez que o hospital atende à normatização de atenção humanizada do recém-nascido de baixo peso (menos de 2500g), do Ministério da Saúde. Todos esses bebês ficavam na Unidade de Terapia Intensiva Neonatal (UTIN) ou no berçário de médio risco, até sua alta. As mães podiam permanecer junto deles 24 horas por dia. Para participar dos grupos, as mães não levavam seus bebês, mesmo quando já liberados da UTIN, para terem maior liberdade de movimentos.

Esta pesquisa iniciou-se por uma entrevista semi-dirigida junto às mães, com o objetivo de traçar seu histórico gestacional. Em seguida, foi feita a aplicação da Escala de Ansiedade, Depressão e Irritabilidade (IDA), a qual foi utilizada por seu valor clínico, pois combina medidas de ansiedade, depressão e irritabilidade (Snaith, Constantopoulos, Jardine \& McGuffin, 1978), valor este que vem sendo atestado em programas de intervenção com mães (Gasparetto, 1998; Scott \& Stradling, 1987). Nesta escala, os resultados podem ser classificados em Normal, Limítrofe e Patológico. A validação das subescalas de depressão e ansiedade da IDA foi feita por meio de correlação com a escala psiquiátrica de Hamilton (Hamilton, 1959).

Aplicou-se também o Inventário de Percepção Neonatal (IPN-I), que avalia o grau de percepção da evolução psicofuncional que a mãe tem de seu bebê em comparação com outros bebês. Broussard e Hartner (1971) levantaram critérios rigorosos para verificar o alto grau de validade do instrumento, comprovando que este inventário tem grande utilidade no registro da percepção materna no período neonatal. Pesquisas (Gasparetto, 1998; Perry, 1983) têm utilizado o IPN-I, inclusive estudando sua associação com o desenvolvimento emocional do bebê. 
A seguir foram efetuadas 16 intervenções grupais semanais com atividades lúdicas (sensório-motoras, simbólicas e de regras ou de socialização), associadas a gráficas, de 60 minutos de duração, segundo modelo piagetiano, isto é, priorizando o predomínio da descontração da assimilação sobre a tensão da acomodação, ou seja, por meio da expressão livre e espontânea. Os brinquedos foram selecionados visando a movimentação física (jogo de varetas), a representação materna de situações do dia-a-dia (bonecos bebês, berços, utensílios de cozinha), e jogos de regras que estimulavam o contato social e o foco na atividade desenvolvida (jogo da memória, quebra-cabeça). O material lúdico contemplou, portanto, as três grandes modalidades lúdicas descritas por Piaget (1978): sensório-motoras, simbólicas e de regras ou socialização. Foi também disponibilizado material gráfico diversificado, possibilitando expressão simbólica não verbal através de desenhos livres.

Os encontros seguiram um roteiro flexível com apresentação inicial do grupo, já que era aberto, com escolha e desenvolvimento do jogo/desenho pelo grupo e fechamento, com exposição e discussão dos temas que haviam aflorado, com as emoções e sentimentos vivenciados na situação, com apoio da psicóloga.

Este estudo foi aprovado pelo Comitê de Ética em Pesquisa da Faculdade de Medicina do ABC, protocolo n 198/2006, em 2/8/2006, e todos os participantes assinaram o Termo de Consentimento Livre e Esclarecido, antes de sua inclusão na amostra.

\section{Resultados e Discussão}

O perfil gestacional das mães revelado na entrevista mostrou tratar-se do segundo ciclo gestacional, em 75\% dos casos. Também 75\% das mães revelaram que já haviam sofrido aborto ou óbito fetal, dado este que confirma estudos de Kliegman (1996) que atestam que o nascimento de um recém-nascido com baixo peso pode estar associado à história materna de ineficiência reprodutiva (relativa infertilidade, abortos, outros bebês pré-termo ou de baixo peso).

Em relação ao tempo de gestação, os dados indicaram uma média de 31 semanas. O tempo de internação da amostra revelou grandes diferenças de caso para 272 caso, sendo que 75\% das mães permaneceram 63,5 dias no hospital, resultado que coincide com o de pesquisas que relatam um período médio de permanência hospitalar acima de 30 dias (Ruiz et al., 2005; Valle, 2002; Gasparetto, 1998). O sentimento predominante das mães após o parto, declarado na entrevista foi de Medo.

A análise dos resultados da IDA revelou níveis de ansiedade e depressão classificados como patológicos, em 75\% das mães, mas nível de irritabilidade, normal. Estes dados comprovam que mães de bebês pré-termo apresentam alta frequência de sintomas de depressão, sendo que este estado emocional gera dificuldade do bebê em desenvolver seu apego à mãe (Poehlmann \& Fiese, 2001).

Os altos índices relativos à ansiedade e depressão em mães de recém-nascidos pré-termo comprovam estudos e atestam como o nascimento de um recém-nascido pré-termo pode gerar ansiedade materna, havendo um descompasso entre o bebê que era esperado e o que nasce: um recém-nascido pequenino, com aspecto estranho, musculatura e tonicidade reduzidas, cabeça grande, pele viscosa e brilhante, que a mãe não pode segurar nos braços, mas que está sendo manipulado constantemente pela equipe de saúde (Ruiz et al., 2005; Schmücker et al., 2005; Brum \& Scherman, 2004).

Os dados relativos ao IPN-I revelaram que 75\% das mães estudadas demonstraram ter uma percepção positiva quanto à evolução psicofuncional de seus bebês, o que tem uma significação prognóstica favorável, uma vez que pesquisadores (Perry, 1983) que utilizaram o IPN-I comprovaram que quando o bebê é percebido de forma negativa pela mãe, aumenta a possibilidade de que ele venha a apresentar comprometimento emocional ao longo do desenvolvimento.

Acompanhamento longitudinal no primeiro ano de vida (Fraga et al., 2008) de bebês prematuros considerados de baixo risco por suas mães também comprovou como esta visão contribui para o bom desenvolvimento dos mesmos. A dialética da organização psicofuncional do bebê prematuro é mediada pela interação estabelecida fundamentalmente com sua mãe, sendo que sua falta compromete seu desenvolvimento em geral. Este risco justifica projetos interventivos como este, que buscam dar suporte emocional a essas mães, favorecendo seu contato afetivo com seus bebês (Casanova et al., 2002; Pinto, Vilanova \& Vieira, 1997; Pinto 2004; Valle, 2002), dentre estes, os que abordam o Método Canguru (Brasil, 2002; Venâncio \& Almeida, 2004). 
Comprovando estes estudos, a análise qualitativa da intervenção lúdico-gráfica aqui apresentada mostrou uma evolução positiva do quadro emocional das mães, o que favoreceu a aceitação de sua maternidade. O estudo obteve adesão da totalidade das participantes que haviam respondido ao IDA e ao IPN-I. A média de frequência foi de cinco mães por encontro, com variação das mesmas, uma vez que várias saíam por alta dos bebês, ao mesmo tempo em que outras entravam por haverem dado à luz.

As intervenções criaram situações que propiciaram maior movimentação corporal espontânea e prazerosa, o que favoreceu a flexibilização tono-postural das mães, no início muito tenso, como já verificado em estudos anteriores (Carvalho et al., 2008; Melnyk et al., 2008). Esta reorganização corporal, sensório-motora, associada à interação prazerosa do grupo favoreceu a expressão de representações mentais evocadas e/ou imaginadas, o que comprova a leitura piagetiana de que as manifestações simbólicas se alicerçam e se dinamizam via corpo. Os jogos, em especial os de socialização ou de regras, contribuíram para a interação e suporte do grupo. Em suma, a integração flexível das três modalidades lúdicas (sensório-motoras, simbólicas e de regras) contribuiu para favorecer a manifestação de temas ansiógenos e a externalização de sentimentos e emoções daí decorrentes.

De forma complementar, verificou-se que as atividades grupais levaram à formação de um espírito de equipe, no qual, com progressiva coesão, havia espaço e escuta para as mães dizerem livremente o que sentiam e pensavam, temas que, muitas vezes, eram compartilhados e compreendidos pelas demais. Esse apoio, uma vez sentido, propiciado e associado ao desenvolvimento das atividades lúdico-gráficas não dirigidas, livres e espontâneas, gerou por sua vez uma crescente reorganização corporal. Esta dinâmica espiralada ascendente fortaleceu a interação dinâmica corpo-símbolo-social em suas duas vias, ou seja, o corpo, ao mesmo tempo, base estrutural e funcional da construção simbólica, afirmou-se na interação social contextualizada, continuamente, à medida que as mães conseguiam se inserir de forma ativa e efetiva nos grupos via manifestações simbólicas. Essas considerações são relevantes para esta população enfocada, uma vez que a mãe do bebê pré-termo tem a sua imagem corporal e a de seu bebê fragilizadas, o que dificulta o contato físico ente ambos, como já comprovado (Carvalho \& Gomes, 2005; Scochi et al., 2004). Essa dificuldade foi progressiva e relativamente vencida, segundo depoimentos das mães, que, aderindo ao Método Canguru adotado pelo hospital, conseguiam uma interação física com seus bebês de forma mais tranquila, o que mostra como esta modalidade de intervenção adapta-se de forma positiva a hospitais que desenvolvem esse método.

No processo interventivo, em suma, pode-se distinguir uma evolução similar geral, respeitando-se o ritmo de cada mãe, que pode ser assim resumida:

No início, associado ao quadro de ansiedade e depressão constatado pela IDA, com o desconhecimento do grupo e do que lhe seria solicitado, um sentimento de desconforto e insegurança, manifestava-se por uma postura de isolamento, com tono-postural rebaixado e comunicação verbal e gestual muito reduzida. Contudo, já se podia observar que as mães que começavam a frequentar o grupo atendiam ao apelo das "veteranas" e mostravam já interesse pelas atividades e pelo que era conversado sobre os bebês.

No transcorrer das sessões, observou-se que as atividades lúdico-gráficas, desenvolvidas em ambiente grupal acolhedor, criaram condições de as mães expressarem seu sofrimento frente a vários temas, dentre os quais: sua dificuldade e mal-estar em entrar em contato físico com um bebê tão frágil; seu conflito e ambivalência entre o bebê idealizado e o nascido; sua culpa pelo parto pré-termo; por vezes, sua impossibilidade de amamentar seu bebê; sua falta de casa e do companheiro; seu desejo de estar em um outro lugar, cheio de vida e tranquilidade. Essa abertura fez-se acompanhar de uma reorganização postural e mental, com maior facilidade de comunicação, manifestando já maior interação espontânea e prazerosa. No decorrer da intervenção, constatou-se que as mães "veteranas", que já haviam participado de outros encontros, agiam como suporte das iniciantes, encorajando-as a participar. Sua atitude mais solta e confiante gerou segurança nas que entravam.

Mais próximo à alta do bebê, já bem à vontade no ambiente proposto e entrosadas ao grupo, os temas relativos à ansiedade e angústia da experiência materna vivida cedeu pouco a pouco lugar para os de situações 
concretas do dia-a-dia, relativas à volta para casa e aos preparativos para receber o bebê. A maternidade mostrou-se, portanto, menos assustadora e o contato com a realidade vivida mais aceito e efetivo, indicadores estes de um movimento de equilibração emocional, com diminuição da ansiedade e da depressão.

Devido à pressão do tempo relativa ao processo da alta, sem possibilidade de definição prévia, os instrumentos utilizados no momento da internação, IDA e IPN-I, não puderam ser reaplicados, o que impossibilitou que os dados observados no acompanhamento das intervenções fossem testados.

A fim de ilustrar este processo, apresenta-se uma síntese evolutiva de uma das mães, que aqui trataremos por Rita, nome fictício. Casada há seis anos, com 24 anos, tem o $1^{\circ} \mathrm{grau}$ e trabalha como auxiliar de limpeza. Esta foi sua primeira gestação, a qual foi esperada e planejada. Realizou pré-natal, tendo desenvolvido um quadro de hipertensão gestacional. Não sabia que seu bebê podia nascer antes do tempo. Teve parto cesariana. Seu primeiro sentimento referido após o parto foi de medo. Apresentou um quadro de alta ansiedade após o parto (escore 10, nível patológico, pela IDA), e sua expectativa em relação ao bebê foi positiva (IPN-I). 0 peso do bebê ao nascer foi de 946 gramas; a idade gestacional de 29 semanas e o tempo total de hospitalização, de 94 dias.

Seu primeiro momento caracteriza-se por manifestação da ansiedade frente à disparidade entre a representação do bebê idealizado versus o bebê real e pela angústia gerada pelo medo de prejudicá-lo. No primeiro grupo em que participa, com sete mães, Rita mostra-se tímida e isolada. A atividade gráfica havia sido escolhida. Enquanto desenham, as mães conversam sobre o quadro clínico de seus bebês e das expectativas que têm. Uma das mães começa a chorar relatando que seu bebê não está bem, pois foi descoberto que também tem hidrocefalia. Rita diz que fica muito tempo na UTIN, pensando no que seu bebê ainda vai fazer. Diz que não chora, pois tem que se acalmar para não deixar que ele sofra também. Conta que está desenhando um campo de futebol onde ele ainda vai jogar. Desenha um campo de futebol vazio, sem jogadores. Os desenhos das outras mães têm temáticas predominantes de natureza, com muito verde e sol, e falam sobre o desejo de

274 poder estar nesses lugares onde se sentiriam bem, com alegria e paz. Rita evidencia, assim, a expectativa de que seu bebê se desenvolva de forma saudável, mas que, no momento, sente grande mal estar e precisa se controlar para não externalizar sua dor, temendo prejudicá-lo ainda mais. Observa-se como a combinação de pertencer a um grupo e de estar criando algo seu, por meio simbólico, proporciona-Ihe a liberdade de expressar sua angústia. Neste começo, aparece já o conflito de sentimentos gerado pela expectativa positiva (aquilo que deseja) frente à incerteza da realidade (aquilo que presencia) ao qual o grupo dá suporte para que se manifeste.

Seu segundo momento caracteriza-se por se permitir voltar a falar de sua vida amorosa, com crescente descontração. Em seu $4^{\circ}$ encontro, com seis mães presentes, chega sorridente e mais descontraída. É selecionado pelas mães o jogo da memória. Rita participa com entusiasmo. Ao ver a figura de um gato, diz: "... o gato émeu! Que saudade do meu gato! Já falei com ele por telefone hoje..." (é dia dos Namorados). Refere-se ao companheiro que não vê há dias, em função de sua permanência hospitalar prolongada. Sua fala mobiliza as outras mães, que passama comentar sobre seus companheiros. Evidenciam como sofrem um desgaste físico e emocional, vivenciando uma rotina diária totalmente diferente daquela que conheciam. Falam da angústia de passar dias no hospital sem ir para casa e reencontrar sua família. Continuam jogando, mas mantém o foco da conversa na relação afetiva, principalmente com o pai do bebê, durante toda a atividade. Ao final, no fechamento, é aberta, como sempre, a roda para que cada mãe fale. Todas dizem que as sessões estão Ihes proporcionando alegria e menos tensão. Rita diz que se sentiu muito bem, pois ao ver o gato, lembrou-se de seu amor, o pai de seu bebê. A psicóloga pontua sobre a ansiedade materna ligada à internação do recém-nascido pré-termo e à distância do companheiro, como no caso de Rita, que parece sentir muita falta do marido para apoiá-la no dia-a-dia. Completa observando que o jogo de memória trouxe também lembranças e o quanto é importante manter vivas as nossas ligações.

Seu terceiro momento evidencia sua busca de retomada da realidade vivida, a reintegração de si mesma, cuidando da casa e do bebê, como o juntar as peças do quebra-cabeça. Cantam, sinalizando o assumir mais sereno da maternidade que acolhe e embala. No período 
final da internação do bebê, Rita mostra-se menos ansiosa e mais adaptada à situação hospitalar. O jogo escolhido nesta sessão foi um quebra-cabeça. Mostra-se à vontade, procurando as peças, comunicando-se e sorrindo muitas vezes. Enquanto jogam, as mães conversam sobre a expectativa de alta dos filhos. Por terem dificuldade no jogo, questionam se não falta alguma peça. Incentivadas pela psicóloga a continuar tentando, mantêm atenção. Faltam poucas peças, quando Rita diz que está bem na medida do possível e que ainda está arrumando o quarto de seu filho, já que não deu tempo, pois ele nasceu muito antes! Comenta que o quarto vai ficar lindo e começa a cantar uma cantiga de ninar, ao mesmo tempo em que continua a montagem. O quebra-cabeça revelou a imagem de um berço de bebê, o que deve ter contribuído para que Rita se lembrasse do quarto que está montando para seu filho, imaginando o momento em que o fará adormecer, ou seja, mostrando seu desejo de exercer sua função de maternagem. As mães finalizam rindo e comentam que foi muito bom montar aquele jogo, mas que foi necessário prestar atenção. Rita comenta que não estava faltando peça, mas que elas é que não estavam conseguindo montar porque estavam se lembrando dos seus bebês. A psicóloga faz referência à expectativa da alta hospitalar e ao desejo que as mães têm de exercer o papel materno esperado, dizendo ter notado na fala e no canto das mães um comportamento de proteção e acolhimento, fundamental para o desenvolvimento dos bebês. Pontua ainda, que a espontaneidade e a tranquilidade mostradas, indica terem conseguido lidar e minimizar seu nível de ansiedade. Diz também que o jogo promove a solução de um problema onde se utiliza, ao mesmo tempo, a inteligência e a emoção e que, na vida, também é preciso juntar os dois.

Os momentos aqui selecionados ilustram o movimento evolutivo de Rita em relação ao controle sua de ansiedade, no início classificada como patológica, pela IDA e a aceitação da maternidade vivida, com as atribuições, responsabilidades e alegrias dela decorrentes. Observa-se também o voltar a assumir sua feminilidade e seu relacionamento amoroso sem sensação de culpa pelo parto pré-termo. Durante os 94 dias de hospitalização do seu bebê, sua ansiedade regrediu, observando-se a cada semana, através de sua participação nos grupos, movimentos mais soltos, comunicação mais espontânea e expressão facial mais alegre, sorrisos mais frequentes, indicadores estes de que reassumia seu bem-estar perante a vida.

A evolução dos encontros proporcionou uma elaboração progressiva do momento vivenciado, assim como facilitou o fortalecimento e a descoberta de ferramentas para o enfrentamento dos desafios do pós-parto. As atividades grupais desenvolvidas com recursos lúdicos e gráficos proporcionaram uma interação social prazerosa, que possibilitou deslocar o foco da situação vivida para uma atividade descontraída, com significado simbólico, o que, por seu lado, permitiu a emergência menos sofrida de temas ansiógenos, relacionados ao nascimento do bebê antes do tempo.

A utilização de recursos simbólicos mostrou-se também positiva por propiciar opções diversas, segundo a escolha e o momento da mãe. A "roda de conversa", ao final de cada encontro, fazendo o fechamento do dia e conjugando-o ao processo do parto prematuro, com tempo e espaço para cada uma falar de si e ouvir a outra, teve importância decisiva na elaboração da representação do bebê e da interação mãe-bebê, vendo como ele realmente havia nascido, e não como o tinha idealizado.

Esses dados confirmam os constatados por outros estudos desenvolvidos com mães de recém-nascidos pré-termo hospitalizados (Scochi et al., 2004), os quais indicam que o brincar contribui com o processo de adaptação e equilíbrio diante da realidade vivida pela mãe, além de se caracterizar como uma forma de assistência humanizada à saúde.

\section{Considerações Finais}

Com o avanço da medicina fetal, cresce dia a dia o número de recém-nascidos pré-termo que sobrevive. Neste sentido, notoriamente, há uma preocupação contínua com o atendimento destes bebês, constatando-se, frequentemente, a importância de uma interação materna afetiva e efetiva em relação ao processo de desenvolvimento.

$\mathrm{O}$ andamento da pesquisa comprovou o alto nível de ansiedade das mães logo após o parto prematuro, o que justifica a importância deste trabalho para a saúde física, psíquica e social da mãe e sua interação com o bebê, o que interfere diretamente no processo 
de desenvolvimento ao longo do tempo, caracterizando-se assim, como uma ação psicoprofilática. Verificou-se que a intervenção grupal lúdico-gráfica possibilitou uma re-equilibração emocional ao longo da internação do recém-nascido, podendo, portanto ser considerada uma situação benéfica para ambos, favorecendo a interação necessária para um desenvolvimento integral e saudável do bebê.

A proposta metodológica de introduzir a atividade lúdico-gráfica grupal para mães de recém-nascidos pré-termo hospitalizados, no próprio ambiente hospitalar, contribuiu também para a visão da mãe do ambiente hospitalar, como um espaço de transformação e aprendizagem da função materna, em sintonia com o Método Canguru.

O estudo aqui apresentado atende a medidas de humanização do atendimento perinatal, pré-natal e nascimento, que contemplam uma atenção de qualidade, humana e individualizada, às gestantes, aos recém-nascidos e às famílias.

\section{Referências}

Brasil. Ministério da Saúde. (2002). Atenção humanizada ao recém-nascido de baixo peso: método Canguru. Brasília: Ministério da Saúde.

Broussard, E. R., \& Hartner, M. (1971). Further considerations regarding maternal perceptions of the firstborn. In J. Heellmuth (Org.), The exceptional infant: studies in abnormalities (pp.81-104). New York: Brunner/Mazel.

Brum, E. H. M., \& Schermann, L. (2004). Vínculos iniciais e desenvolvimento infantil: abordagem teórica em situação de nascimento de risco. Ciência \& Saúde Coletiva, 9 (2), 475-476.

Carvalho, A. E. V., Martinez, F. E., \& Linhares, M. B. M. (2008). Maternal anxiety and depression and development of prematurely born infants in the first year of life. The Spanish Journal of Psychology, 11 (2), 600-608.

Carvalho, M., \& Gomes, M. A. S. M. (2005). A mortalidade do prematuro extremo em nosso meio: realidade e desafios. Jornal de Pediatria, 81 (1), 111-118.

Casanova, L. D., Valle, L. M. S., \& Santos, W. A. (2002). Humanização das unidades neonatais. In C. A. Segre (Org.), O RN (pp.866-869). São Paulo: Sarvier.

Costa, J. B., Mombelli, M. A., \& Marcon, S. S. (2009). Avaliação do sofrimento psíquico da mãe acompanhante em alojamento conjunto pediátrico. Estudos de Psicologia (Campinas), 26 (3), 317-325. doi: 10.1590/S0103-166X200900 0300005.

Cruvinel, F., \& Macedo, E. C. (2007). Interação mãe-bebê 276 pré-termo e mudança no estado de humor: comparação do Método Mãe-Canguru com visita na Unidade de Terapia Intensiva Neonatal. Revista Brasileira de Saúde Materno-Infantil, 7 (4), 449-455.

Fraga, D. A., Linhares, M. B. M., Carvalho, A. E. V., \& Martinez, F. E. (2008). Desenvolvimento de bebês nascidos pré-termo e indicadores emocionais maternos. Psicologia: Reflexão e Crítica, 21 (1), 33-41.

Gasparetto, S. (1998). Desenvolvimento de um programa de intervenção para mães de bebês pré-termo. Tese de doutorado não-publicada, Instituto de Psicologia, Universidade de São Paulo.

Goulart, A. L. (2004). Assistência ao recém-nascido prétermo. In B. I. Kopleman, A.M.N. Santos \& A.L. Goulart. Diagnóstico e tratamento em neonatologia (pp.17-23). São Paulo: Atheneu.

Hamilton, M. (1959). The assessment of anxiety states by rating. British Journal of Medical Psychology, 32 (1), 50-55.

Kliegman, R. M. (1996). The high-risk infant. In R. E. Berhrman, R. M. Kliegman \& A. M. Arvin. Textbook of pediatric (pp.547-550). New York: W. B. Sauders.

Melnyk, B. M., Crean, H. F., Feinstein, N. F., \& Fairbanks, E. (2008). Maternal anxiety and depression after a premature infant's discharge from the neonatal intensive care unit: explanatory effects of the creating opportunities for parent empowerment program. Nursing Research Journal, 57 (6), 383-94.

Oliveira, S. S. G., Dias, M. G. B. B., \& Roazzi, A. (2003). O lúdico e suas implicações nas estratégia de regulação das emoções em crianças hospitalizadas. Psicologia: Reflexão e Crítica, 16 (1), 1-13.

Padovani, F. H. P., Linhares, M. B. M., Carvalho, A. E. V., Duarte, G., \& Martinez, F.E. (2004). Avaliação de sintomas de ansiedade e depressão em mães de neonatos pré-termo durante e após hospitalização em UTI-Neonatal. Revista Brasileira de Psiquiatria, 26 (4), 251-254.

Perry, S. E. (1983). Parents' perceptions of their newborn following structured interactions. Nursing Research Journal, 32 (4), 208-212.

Piaget, J. (1973). Biologia e conhecimento. Petrópolis: Vozes.

Piaget, J. (1978). A formação do símbolo na criança. Rio de Janeiro:Zahar.

Pinto, E. B. (2004). Baby's psychofunctional symptoms and parents/baby therapeutic consultations. Estudos de Psicologia (Natal), 9 (3), 451-457.

Pinto, E. B., Vilanova, I. C. P., \& Vieira, R. M. (1997). O desenvolvimento do comportamento da criança no primeiro anos de vida: padronização de uma escala para a avaliação e o acompanhamento. São Paulo: Casa do Psicólogo.

Poehlmann, J., \& Fiese, B. H. (2001). The interaction of maternal and infant vulnerabilities and developing attachment relationships. Developmentand Psychopathology, $13(1), 1-11$

Ruiz, A. L., Ceriani Cernadas, J. M., Cravedi, V., \& Rodríguez, D. (2005). Estrés y depresión en madres de prematuros: un programa de intervención. Archivos Argentinos de Pediatría, 103 (1), 36-45. 
Ryding, E. L. (2008). Identify and treat perinatal depression: for the sake of the baby! Acta Pædiatrica, 97 (6), 697-698.

Schmücker, G., Brisch, K.-H., Kohntop, B., Betzler, S., Osterle, M., Pohlandt, F., et al. (2005). The influence of prematurity, maternal anxiety, and infants' neurobiological risk on mother-infant interactions. Infant Mental Health Journal, 26 (5), 423-441.

Scochi, C.G.S, Brunherotti, M.R., Fonseca, L.M.M., Nogueira, F.S., Vasconcelos, M.G.L., \& Leite, A.M. (2004). Lazer para mães de bebês de risco hospitalizados: análise da experiência na perspectiva dessas mulheres. Revista Latino-Americana de Enfermagem, 12 (5), 1-15.

Scott, M., \& Stradling, S. (1987). Evaluation of a group programme for parents problem children. Behavioral Psychotherapy, 15 (3), 224-239.

Snaith, R., Constantopoulos, A., Jardine, M., \& McGuffin, P. (1978). A clinical scale for the self assessment of irritability (IDA). British Journal of Psychiatry, 132 (2), 164-171.

Thomaz, A. C. P., Lima, M. R. T., Tavares, C. H. F., \& Oliveira, C. G. (2005). Relações afetivas entre mães e recém nascidos a termo e pré-termo: variáveis sociais. Estudos de Psicologia (Natal), 10 (1), 139-146.

Valle, L. M. S. (2002). Fatores de alto risco e ansiedade em mães de recém nascido pré-termo. Dissertação de mestrado não-publicada, Instituto de Psicologia, Universidade de São Paulo.

Venancio, S. I., \& Almeida, H. (2004). Método mãe-canguru: aplicação no Brasil, evidências científicas e impacto sobre o aleitamento materno. Jornal de Pediatria, 80 (5), 173-180.

Vieira, T., \& Carneiro, M. S. (2008). O brincar na sala de espera de um ambulatório pediátrico: possíveis significados. In E. Bomtempo, E. G. Antunha \& V. B. Oliveira (Orgs.), Brincando na escola, no hospital, na rua... (2a ed., pp.75-110). Rio de Janeiro: Wak.

Vizziello, G. F., Rebecca, I., \& Calvo, V. (2001). Representaciones maternas, apego y desarrollo en la premadurez. Mudanças, 9, 136-165.

Recebido em: 2/4/2009

Versão final reapresentada em: 5/8/2010

Aprovado em: 11/3/2011 
